\title{
HUBUNGAN PENGGUNAAN AKDR DENGAN KEJADIAN EFEK SAMPING PADA AKSEPTOR AKDR (Di Desa Kates Kecamatan Kauman Kabupaten Tulungagung)
}

Betristasia Puspitasari ${ }^{1}$, Diah Siswati ${ }^{2}$

Akademi Kebidanan Dharma Husada Kediri Jawa Timur

\section{ABTRAK}

AKDR adalah sebuah alat yang dimasukkan melalui saluran serviks dan dipasang dalam uterus. AKDR merupakan suatu metode kontrasepsi jangka panjang yang efektif dengan angka kegagalan rendah. Kontrol rutin setelah pemasangan dapat mencegah akseptor AKDR drop out. Tujuan penelitian ini adalah menganalisis hubungan lama penggunaan AKDR dengan kejadian efek samping pada akseptor AKDR.

Desain penelitian yang digunakan adalah korelasional dengan pendekatan Cross Sectional. Populasi pada penelitian ini adalah seluruh akseptor AKDR di Desa Kates Kecamatan Kauman Kabupaten Tulungagung berjumlah 98 akseptor. Dengan teknik sampling Simple Random Sampling didapatkan sampel sebanyak 78 responden yang dilakukan pada tanggal 27-31 Mei 2016. Variabel independen yaitu penggunaan AKDR dan variabel dependen yaitu efek samping penggunaan AKDR. Pengumpulan data menggunakan kuesioner dan kartu KB, yang diolah dengan editing, coding, scoring dan tabulating. Analisa data dengan Chi Kuadrat.

Hasil penelitian menunjukkan dari 79 responden, 57 responden $(72 \%)$ menggunakan AKDR $>1$ tahun dan 52 responden (66\%) mengalami efek samping pemakaian AKDR. Dari uji statistik menggunakan Chi Kuadrat didapatkan $\chi^{2}$ hitung $=7,12, \chi^{2}$ tabel $=5,991$ dengan $\alpha=0,05$. Dapat disimpulkan bahwa $\chi^{2}$ hitung $>\chi^{2}$ tabel yang artinya $\mathrm{H}_{1}$ diterima.

Dari penelitian diatas dapat disimpulkan bahwa ada hubungan antara penggunaan AKDR dengan kejadian efek samping pada akseptor AKDR. Dengan demikian disarankan akseptor AKDR rutin kontrol untuk mengantisipasi timbulnya efek samping sehingga dapat dilakukan penanganan yang tepat untuk mengatasi efek samping yang terjadi.

Kata Kunci : AKDR, Penggunaan, Efek Samping

Korespondensi: Ds. Sidomulyo RT 002/RW 002 Kec. Semen Kab. Kediri Jawa Timur HP: 085790256810 ,email: betristasya@gmail.com 


\section{Pendahuluan}

Penggunaan AKDR merupakan salah satu usaha manusia untuk menekan kesuburan sejak berabad-abad lalu. Adapun penjelasan tentang metode AKDR adalah sebuah alat yang dimasukkan melalui saluran serviks dan dipasang dalam uterus. AKDR bekerja dengan cara mencegah kehamilan dengan merusak kemampuan hidup sperma dan ovum melalui perubahan pada tuba falopii dan cairan uterus; ada reaksi terhadap benda asing disertai peningkatan leukosit. Kondisi ini mengurangi kesempatan ovum dan sperma bertemu dan menghambat pembuahan. Sebagian percaya bahwa tembaga yang terdapat pada AKDR bersifat toksik terhadap sperma dan ovum (Everett, 2007: 197). Dilihat dari jenisnya, AKDR yang telah beredar terdiri dari dua jenis yaitu AKDR yang mengandung obat: Copper T 380 A, Copper T 200, Copper T 220, Multiload 375, Multiload 250, dan Nova T. Sedangkan AKDR yang tidak mengandung obat: Lippes Loop dan cincin baja tahan-karat tunggal atau ganda (WHO, 2006: 20).

Pemakaian metode KB jelas berperan dalam menurunkan angka kematian ibu dan meningkatkan kelangsungan hidup anak, namun sebagian wanita mungkin enggan memakai suatu kontrasepsi dikarenakan takut akan efek samping yang ditimbulkannya (WHO, 2006: 15).

Dilihat dari keefektifannya, AKDR merupakan salah satu Metode Kontrasepsi Jangka Panjang (MKJP) yang efektif dengan angka kegagalan yang rendah sekitar $0,6 \quad-\quad 0,8$ kehamilan/100 perempuan dalam 1 tahun pertama. Akan tetapi kebanyakan wanita khawatir mengenai nyeri akibat pemasangan AKDR. Selain itu efek samping yang sering timbul dikarenakan pemakaian AKDR dengan obat ataupun tanpa obat adalah amenorea, kejang/kram, perdarahan vagina yang hebat dan tidak teratur, benang yang hilang/gangguan benang, adanya pengeluaran cairan dari vagina/dicurigai adanya Penyakit Radang Panggul (PRP) yang menyebabkan pemakainya tidak nyaman dan menjadi alasan untuk menghentikan pemakaiannya (Sarwono, 2011: MK-86-87).

Sekitar 55\% pemakai AKDR memutuskan untuk beralih pada metode kontrasepsi jangka pendek (Jurnal Kesehatan Masyarakat Nasional, 2011: 143). Didapatkan jumlah akseptor AKDR baru di Indonesia tahun 2015 sebanyak $145.520(7,20 \%)$ akseptor dengan total akseptor AKDR aktif sejumlah 2.020.490 akseptor. Jumlah ini turun $20,18 \%$ jika dibandingkan dengan jumlah akseptor AKDR baru tahun 2014 sebanyak $921.540 \quad(27,38 \%)$ akseptor dengan jumlah peserta akseptor AKDR aktif tahun 2014 sebanyak 3.365.070 akseptor. Dapat disimpulkan bahwa sebanyak $1.344 .580 \quad(25 \%)$ akseptor memilih Drop Out (DO) (BKKBN, 2015). Menurut Harniati (2011) mengatakan bahwa dari jumlah akseptor KB di Kabupaten Tulungagung yang dilayani terus bertambah namun masih ada 2 jenis kontrasepsi yang ternyata masih dibawah target yang ditetapkan yaitu salah satunya AKDR. Dari 3000 akseptor yang ditargetkan, ternyata hanya tercapai 2.673 akseptor baru (89\%). Minimnya peminat AKDR dikarenakan kebanyakan masyarakat masih takut menggunakannya padahal kontrasepsi AKDR paling bagus untuk mencegah kehamilan.

Meskipun AKDR dapat dipakai dalam waktu yang cukup lama, 
pemakaian AKDR yang melebihi masa pemakaian juga dikhawatirkan menimbulkan efek samping yaitu kandungan tembaga yang mengalami dislokasi. Hal ini perlu ditangani dengan segera karena dapat mengakibatkan penyumbatan usus yang disertai nyeri, muntah-muntah dan demam. Atau yang lebih parahnya dapat mengakibatkan peradangan dan perdarahan (Arum \& Sujiatini, 2009: 155).

Pemeriksaan AKDR secara dapat dilakukan oleh ibu secara mandiri oleh ibu dirumah tanpa harus melibatkan bidan. Hal ini lebih menguntungkan karena bila terjadi efek samping seprti benang AKDR hilang ibu akan mengatahuinya sejak dini dan dapat pergi ke bidan untuk diberikan tindakan.

Dari permasalahan diatas solusi yang juga dapat dilakukan adalah penapisan rutin yang sangat diperlukan dalam upaya mencegah akseptor AKDR drop out. Hal tersebut dapat dilakukan dengan kunjungan ulang pada akseptor AKDR sesuai dengan jadwal yang diberikan yaitu 1 bulan setelah pemasangan, setiap 6 bulan, 1 tahun sekali dan sewaktu-waktu apabila terjadi keluhan (Marmi, 2010: 215). Langkah ini diambil sebagai bahan evaluasi agar efek samping yang biasa terjadi dapat ditanggulangi dan tidak berdampak pada drop out-nya jumlah akseptor AKDR.

\section{METODE}

Rancangan penelitian yang akan digunakan dalam penelitian ini adalah penelitian korelasional (hubungan atau asosiasi).Dalam penelitian ini menggunakan pendekatan Cross Sectional. Penelitian Cross Sectional adalah jenis penelitian yang menekankan waktu pengukuran/observasi data variabel independen dan dependen hanya satu kali pada satu saat. Penelitian ini bertujuan untuk mengetahui adakah hubungan penggunaan AKDR dengan kejadian efek samping pada akseptor AKDR di Desa Kates Kecamatan Kauman Kabupaten Tulungagung.

- Dalam penelitian ini populasinya adalah semua akseptor AKDR di Desa Kates Kecamatan Kauman Kabupaten Tulungagung dengan jumlah populasi (N) 98 akseptor.

Sampel dalam penelitian ini adalah sebagian akseptor AKDR di Desa Kates Kecamatan Kuman Kabupaten Tulungagung yang memenuhi kriteria inklusi sejumlah 79 akseptor.

Dengan kriteria sampel:

a. Kriteria Inklusi

1) Akseptor AKDR yang bersedia menjadi responden

2) Akseptor AKDR yang baru dan lama

3) Akseptor AKDR yang berada di wilayah Desa Kates Kecamatan Kuman Kabupaten Tulungagung.

b. Kriteria Eksklusi

1) Akseptor AKDR yang tidak kooperatif

2) Akseptor AKDR yang drop out karena ingin hamil dan menghentikan pemakaian $\mathrm{KB}$

Teknik Sampling yang digunakan adalah Teknik Simple Random Sampling, yaitu pengambilan sampel dengan acak tanpa memperhatikan strata yang ada dalam anggota populasi (Hidayat, $2007: 32$ ).

Dari 98 akseptor, peneliti akan mengambil 79 akseptor untuk diteliti. Pengambilan datanya dilakukan dengan cara memberi nomor pada setiap akseptor kemudian diambil secara acak dengan dilotere hingga mendapatkan jumlah akseptor yang dikehendaki. Dalam penelitian ini 
variabel independennya adalah penggunaan AKDR. Variabel dependen pada penelitian ini adalah efek samping pemakaian AKDR.

HASIL

1. Data Umum

a. Karakteristik akseptor AKDR berdasarkan umur

Tabel 1 Karakteristik Akseptor AKDR Berdasarkan Umur Di Desa Kates Kecamatan Kauman Kabupaten Tulungagung

\begin{tabular}{cccc} 
No & Umur & Frekuensi & Prosentase $(\%)$ \\
\hline 1 & $<20$ tahun & 0 & 0 \\
\hline 2 & $20-35$ tahun & 31 & 39 \\
\hline 3 & $>35$ tahun & 48 & 61 \\
\hline & Total & 79 & 100
\end{tabular}

b. Karakteristik akseptor AKDR berdasarkan pendidikan

Tabel 2 Karakteristik Akseptor AKDR Berdasarkan Pendidikan Di Desa Kates Kecamatan Kauman Kabupaten Tulungagung

\begin{tabular}{clccc} 
No & & Pendidikan & Frekuensi & Prosentase (\%) \\
\hline 1 & SD & 23 & 29 \\
\hline 2 & SMP & 35 & 44 \\
\hline 3 & SMA & 21 & 26 \\
\hline 4 & Perguruan Tinggi & 0 & 0 \\
\hline \multicolumn{2}{c}{ Total } & 79 & 100
\end{tabular}

c. Karakteristik akseptor AKDR berdasarkan pekerjaan

Tabel 3 Karakteristik Akseptor AKDR Berdasarkan Pekerjaan Di Desa Kates Kecamatan Kauman Kabupaten Tulungagung

\begin{tabular}{clcc} 
No & \multicolumn{1}{c}{ Pekerjaan } & Frekuensi & Prosentase $(\%)$ \\
\hline 1 & Ibu Rumah Tangga & 72 & 91 \\
\hline 2 & Swasta & 5 & 6 \\
\hline 3 & Wiraswasta & 0 & 0 \\
\hline 4 & Pegawai Negeri Sipil & 0 & 0 \\
\hline 5 & Lain-lain & 2 & 3 \\
\hline & Total & 79 & 100
\end{tabular}

2. Data Khusus

a. Penggunaan AKDR

Tabel 4 Distribusi Frekuensi Akseptor AKDR Berdasarkan Penggunaan Di Desa Kates Kecamatan Kauman Kabupaten Tulungagung

\begin{tabular}{cccc} 
No & Penggunaan AKDR & Frekuensi & Prosentase $(\%)$ \\
\hline 1 & $<1$ bulan -6 bulan & 3 & 4
\end{tabular}




\begin{tabular}{cccc}
2 & $>6$ bulan -1 tahun & 19 & 24 \\
\hline 3 & $>1$ tahun & 57 & 72 \\
\hline Total & 79 & 100
\end{tabular}

b. Distribusi frekuensi kejadian efek samping pada akseptor AKDR

Tabel 5 Distribusi Frekuensi Kejadian Efek Samping Pada Akseptor AKDR Di Desa Kates Kecamatan Kauman Kabupaten Tulungagung

\begin{tabular}{clcc} 
No & Efek Samping & Frekuensi & Prosentase $(\%)$ \\
\hline 1 & Ada & 52 & 66 \\
\hline 2 & Tidak & 27 & 34 \\
\hline Total & & 79 & 100
\end{tabular}

Tabel 6 Distribusi Frekuensi Kejadian Efek Samping pada Akseptor AKDR di Desa Kates Kecamatan Kauman Kabupaten Tulungagung

\begin{tabular}{clcc} 
No & \multicolumn{1}{c}{ Efek Samping } & Frekuensi & Prosentase (\%) \\
\hline 1 & Amenorea & 0 & 0 \\
\hline 2 & Kejang/kram & 11 & 14 \\
\hline 3 & $\begin{array}{l}\text { Perdarahan pervaginam yang } \\
\text { hebat dan tidak teratur }\end{array}$ & 22 & 28 \\
\hline 4 & $\begin{array}{l}\text { Benang hilang/gangguan } \\
\text { benang }\end{array}$ & 9 & 11 \\
\hline 5 & $\begin{array}{l}\text { Adanya pengeluaran cairan } \\
\text { dari vagina/dicurigai PRP }\end{array}$ & 10 & 13 \\
\hline 6 & Tidak ada efek samping & 27 & 34 \\
\hline & Total & 79 & 100
\end{tabular}

Tabel 7 Distribusi Frekuensi Hubungan Penggunaan AKDR dengan Kejadian Efek Samping Pada Akseptor AKDR Di Desa Kates Kecamatan Kauman Kabupaten Tulungagung Efek Samping

\begin{tabular}{|c|c|c|c|c|c|c|}
\hline & & & Efek & amping & & \\
\hline $\begin{array}{c}\text { Penggun } \\
\text { aan } \\
\text { AKDR }\end{array}$ & $\begin{array}{c}\text { Amen } \\
\text { orea }\end{array}$ & $\begin{array}{c}\text { Kejang } \\
\text { /Kram }\end{array}$ & $\begin{array}{c}\text { Perdara } \\
\text { han } \\
\text { Hebat }\end{array}$ & $\begin{array}{c}\text { Ganggu } \\
\text { an } \\
\text { Benang }\end{array}$ & $\begin{array}{c}\text { Pengelu } \\
\text { aran } \\
\text { Pervagi } \\
\text { nam }\end{array}$ & $\begin{array}{c}\text { Tidak } \\
\text { Ada } \\
\text { Efek } \\
\text { Sampin }\end{array}$ \\
\hline
\end{tabular}

\begin{tabular}{|c|c|c|c|c|c|c|c|c|c|c|c|c|c|c|}
\hline & & & & & & & & & & & & & & \\
\hline & $\mathrm{J}$ & $\%$ & $\mathrm{~J}$ & $\%$ & $\mathrm{~J}$ & $\%$ & $\mathrm{~J}$ & $\%$ & $\mathrm{~J}$ & $\%$ & $\mathrm{~J}$ & $\%$ & $\mathrm{~J}$ & $\%$ \\
\hline$<1$ bulan & 0 & 0 & 1 & 2 & 1 & 2 & 1 & 2 & 0 & 0 & 0 & 0 & 3 & \\
\hline
\end{tabular}

\begin{tabular}{lcccccccccccccc}
-6 bulan & & & & & & & & & & & & & & \\
\hline $\begin{array}{l}> \\
-1 \text { bulan }\end{array}$ & 0 & 0 & 5 & 6 & 5 & 6 & 1 & 2 & 3 & 4 & 5 & 6 & 19 & 23 \\
\hline$>1$ tahun & 0 & 0 & 5 & 6 & 16 & 20 & 7 & 9 & 7 & 9 & 22 & 28 & 57 & 71 \\
\hline Jumlah & 0 & 0 & 11 & 14 & 22 & 28 & 9 & 11 & 10 & 13 & 27 & 34 & 79 & $\begin{array}{c}10 \\
0\end{array}$
\end{tabular}

d. Analisis uji statistik

Berikut analisis uji statistik menggunakan uji Chi Kuadrat. 
Tabel 8 Tabel Silang Hubungan Penggunaan AKDR Dengan Kejadian Efek Samping Pada Akseptor AKDR Di Desa Kates Kecamatan Kauman Kabupaten Tulungagung

Efek Samping

\begin{tabular}{cccccccc}
\multirow{2}{*}{ Penggunaan AKDR } & \multicolumn{3}{c}{ Efek Samping } & \multicolumn{2}{c}{ Total } \\
\cline { 2 - 6 } & \multicolumn{2}{c}{ Ada Efek } & \multicolumn{2}{c}{ Tidak Ada } & & \\
\cline { 2 - 6 } & $\mathrm{Jml}$ & $\%$ & $\mathrm{Jml}$ & $\%$ & $\mathrm{Jml}$ & $\%$ \\
\hline$<1$ bulan -6 bulan & 3 & 4 & 0 & 0 & 3 & 4 \\
\hline$>6$ bulan -1 tahun & 14 & 18 & 5 & 6 & 19 & 24 \\
\hline$>1$ tahun & 35 & 44 & 22 & 28 & 57 & 72 \\
\hline \multicolumn{2}{c}{ Total } & 52 & 66 & 27 & 34 & 79 & 100 \\
\hline \multicolumn{2}{c}{$\chi^{2}$ hitung $=7,12, \chi^{2}$ tabel $=5,991 \alpha=0,05$} & $\mathrm{dk}=2$ &
\end{tabular}




\section{Diskusi}

\section{Penggunaan AKDR di Desa Kates Kecamatan Kauman Kabupaten Tulungagung}

Berdasarkan hasil penelitian pada tabel 4 didapatkan bahwa sebagian besar responden menggunakan AKDR $>1$ tahun yaitu sebanyak 57 responden (72\%). Hal ini juga ditunjang dengan data umum hasil penelitian yang tercantum pada tabel IV.1 yang menunjukan bahwa sebagian besar umur responden adalah $>35$ tahun yaitu sebanyak 48 responden (61\%).

AKDR adalah sebuah alat yang dimasukkan melalui saluran serviks dan dipasang dalam uterus. AKDR memiliki benang yang menggantung turun ke dalam vagina, yang dapat diperiksa oleh wanita guna memastikan alat tersebut pada posisi yang benar (Everett, 2007: 197). Menurut Sarwono (2011: MK-80), profil AKDR adalah sangat efektif, reversibel dan berjangka panjang (dapat sampai 10 tahun: CuT-380A).

Tingginya tingkat kenyamanan ibu memakai AKDR terbukti dari lamanya penggunaan AKDR itu sendiri. Timbulnya kenyamanan tersebut sejurus dengan adanya kepercayaan yang timbul pada ibu selama memakai alat kontrasepsi yang sedang dipakainya. AKDR berbeda dengan KB hormonal yang dapat menyebabkan pertambahan berat badan, pusing, dan kadang mual karena AKDR sendiri merupakan salah satu kontrasepsi dengan efek samping yang minimal dan tidak mengandung hormon. Ditambah lagi adanya salah seorang ibu yang sudah menjadi akseptor KB lestari didaerah tersebut. Hal ini membuktikan bahwa AKDR sudah mendapatkan tempat dan kepercayaan dari pemakainya. Pemakaian AKDR sendiri dianjurkan untuk semua kalangan umur. Fakta yang didapat dari penelitian menunjukkan bahwa kebanyakan responden yang menggunakan AKDR berumur $>35$ tahun yaitu sebanyak 48 responden (61\%). Hal ini karena pemakaian AKDR yang berjangka panjang dan sebagian responden merupakan akseptor lama yang masa pakai kontrasepsinya habis memutuskan untuk bongkar-pasang AKDR lagi karena sudah merasa cocok. Hal tersebut yang menyebabkan kebanyakan pemakaian AKDR $>1$ tahun dengan umur $>35$ tahun. Peneliti menganjurkan agar ibu yang masa pakai AKDRnya habis untuk berlanjut menggunakan kontrasepsi dikarenakan seorang wanita masih bisa hamil selama masih mendapatkan siklus bulanannya (menstruasi). Pada usia $>35$ tahun merupakan sebuah fase dimana seorang ibu harusnya tidak hamil lagi namun pada kenyataanya rahim seorang ibu masih sangat mungkin untuk menerima adanya kehamilan. Banyak komplikasi yang akan terjadi akibat hamil diusia tua meliputi perdarahan, kegagalan kehamilan atau bayi lahir sebelum/melebihi waktu yang telah ditentukan. Untuk mencegah hal tersebut soerang ibu diharuskan memakai kontrasepsi untuk mencegah kehamilan. Salah satu kontrasepsi yang dianjurkan untuk ibu yang sudah masuk dalam fase tidak hamil lagi adalah steril dan opsional selanjutnya adalah AKDR.

Efek Samping Pada Akseptor AKDR di Desa Kates Kecamatan Kauman Kabupaten Tulungagung

Berdasarkan hasil penelitian pada tabel 5 dari 79 responden didapatkan sebanyak 52 responden $(66 \%)$ mengalami efek samping pemakaian AKDR. Dapat diuraikan dari tabel 6 bahwa sebanyak 11 responden (14\%) mengalami efek samping kejang/kram, sebanyak 22 responden (28\%) mengalami perdarahan pervaginam yang hebat dan tidak teratur, sebanyak 9 responden $(11 \%)$ mengalami benang hilang/gangguan benang, dan 10 responden $(13 \%)$ lainnya mengalami pengeluaran cairan dari vagina/dicurigai PRP dan tak satupun responden $(0 \%)$ yang mengalami efek samping amenorea. 
Efek samping yang umum timbul akibat pemakaian AKDR sendiri meliputi amenorea, kejang/kram, perdarahan vagina yang hebat dan tidak teratur, benang hilang/gangguan benang, dan adanya pengeluaran cairan dari vagina /dicurigai PRP (Saifuddin, 2011: MK-87).

Dari hasil penelitian didapatkan bahwa sebagian besar akseptor AKDR mengalami efek samping. Seperti yang tertulis pada teori diatas bahwa pemakaian AKDR akan menimbulkan efek samping pada pemakaiannya. Pada dasarnya, pemasangan AKDR harus dilakukan oleh petugas kesehatan yang telah terlatih dan harus mengikuti peraturan yang ditentukan. Setelah pemasangan AKDR ibu biasanya sudah diberikan konseling tentang efek samping apa saja yang mungkin terjadi selama pemakaian AKDR terutama pada awal pemakaian.

Pada responden yang mengalami efek samping perdarahan pervaginam yang hebat dan tidak teratur didapatkan bahwa sebelum pemakaian AKDR sebagian responden mengatakan menstruasinya memang sudah banyak, jadi pada sebagian responden hal ini tidak menjadi efek samping pemakaian AKDR. Berbeda jika responden sebelumnya mendapatkan menstruasi normal namun setelah pemakaian AKDR pengeluaran darah haidnya menjadi banyak, sehingga dapat menyebabkan pusing, lemas bahkan pingsan. Hal tersebut akan sangat mengganggu. Namun hal ini dapat ditanggulangi dengan menambah asupan makanan dan mengkonsumsi tablet penambah darah agar efek samping tersebut bisa sedikit berkurang.

Hubungan Penggunaan AKDR Dengan Kejadian Efek Samping Pada Akseptor AKDR Di Desa Kates Kecamatan Kauman Kabupaten Tulungagung

Dari hasil uji analisis menggunakan Chi Kuadrat didapatkan nilai $\chi^{2}$ hitung 7,12 . Bila dibandingkan dengan nilai $\chi^{2}$ tabel $(\alpha=0,05)$ didapatkan 5,991 maka $\chi^{2}$ hitung $>\chi^{2}$ tabel yang artinya bahwa ada hubungan yang bermakna antara lama penggunaan AKDR dengan kejadian efek samping pada akseptor AKDR di Desa Kates Kecamatan Kauman Kabupaten Tulungagung.

Efek samping adalah perubahan sistem, alat, dan fungsi tubuh yang timbul akibat dari penggunaan alat atau obat kontrasepsi dan tidak berpengaruh serius terhadap klien (Kamus Istilah $\mathrm{KKB}, 2011)$.

Pemakaian AKDR memiliki banyak keuntungan dalam penakaiannya salah satunya adalah AKDR merupakan satusatunya kontrasepsi yang dapat dikontrol oleh ibu sendiri dirumah. Setelah pemasangan AKDR pun ibu tidak perlu mengeluarkan biaya tambahan lagi. AKDR merupakan kontrasepsi yang ekonomis dan dapat dipakai dalam jangka waktu yang lama. Selain keuntungan, AKDR juga memiliki kerugian dalam penggunaannya sendiri yaitu munculnya efek samping. Pada awal pemasangan ibu diharapkan tidak bingung karena setelah pemasangan bidan sudah memberikan konseling pasca-pemasangan AKDR.

Dari tabel diatas dapat dilihat bahwa 52 responden (66\%) mengalami efek samping pemakaian AKDR. Dari tabel 6 juga dapat diuraikan bahwa sebanyak 22 responden $(28 \%)$ mengalami efek samping berupa perdarahan pervaginam yang hebat dan tidak teratur.

Efek samping yang umum timbul akibat pemakaian AKDR sendiri meliputi amenorea, kejang/kram, perdarahan vagina yang hebat dan tidak teratur, benang hilang/gangguan benang, dan adanya pengeluaran cairan dari vagina /dicurigai PRP (Saifuddin, 2011: MK-87).

Efek samping yang dialami setiap responden berbeda antara satu dengan responden lain. Mulai dari faktor pemakaian AKDR, apakah ibu masih baru atau sudah lama. Dapat juga dilihat 
dari segi umur ibu, semakin tua umur ibu juga dapat mempengaruhi efek samping yang terjadi. Kegiatan ibu sehari-hari juga dapat memicu terjadinya efek samping seperti terjadinya pengeluaran cairan pervaginam dapat disebabkan karena ibu memakai celana dalam yang ketat dan tidak menyerap keringat sehingga daerah kewanitaan ibu menjadi lembab. Kebanyakan ibu yang mengalami perdarahan pervaginam yang hebat dan tidak teratur terjadi akibat pemasangan AKDR karena ibu mengatakan bahwa sebelum pemakaian AKDR setiap menstruasi pengeluaran darah pervaginamnya normal, namun setelah pemakaian menjadi lebih banyak dibanding setelah pemakaian. Disini pengetahuan ibu tentang AKDR akan sangat membantu agar ibu tidak bingung apabila hal itu terjadi.

Sesuai dengan tabel .2 bahwa hampir setengah dari responden berpendidikan SMP yaitu 35 responden (44\%).

Menurut Nursalam (2003) semakin tinggi tingkat pengetahuan seseorang, maka semakin mudah menerima informasi sehingga semakin banyak pula pengetahuan yang dimiliki. Hal ini sesuai dengan pendapat Y.B Mantra yang dikutip oleh Notoatmodjo (2003), bahwa pendidikan dapat mempengaruhi seseorang termasuk juga perilaku sesorang akan pola hidup terutama dalam termotivasi untuk sikap berperan serta dalam pembangunan kesehatan (Wawan, 2010:16).

Seperti yang dikemukakan oleh teori diatas bahwa semakin tinggi tingkat pengetahuan seseorang maka akan

\section{DAFTAR PUSTAKA}

Arikunto, Suharsimi. 2013. Prosedur Penelitian Suatu Pendekatan Praktik. Jakarta: Rineka Cipta.

Arum, D. N. Setya \& Sujiatini, 2009. Panduan Lengkap Pelayanan KB Terkini. Jogjakarta: Nuha Medika. semakin mudah dalam menerima informasi yang didapat. Informasi yang didapatkan ibu pasca-pemasangan AKDR merupakan informasi yang masih baru dan belum didapatkan oleh ibu sebelumnya. Jadi sangat wajar apabila hal ini mengakibatkan ibu memahami informasi ini secara mentah sehingga ketika terjadi efek samping pemakaian AKDR ibu menganggapnya biasa atau bahkan ibu tidak mengetahuinya. Apalagi untuk ibu yang baru pertama menggunakan

\section{SIMPULAN}

1. Penggunaan AKDR di Desa Kates Kecamatan Kauman Kabupaten Tulungagung didapatkan 57 responden dengan lama penggunaan $>1$ tahun $(72 \%)$.

2. Kejadian efek samping pada akseptor AKDR di Desa Kates Kecamatan Kauman Kabupaten Tulungagung didapatkan 52 responden (53\%) mengalami efek samping pemakaian AKDR dan hampir setengah dari responden mengalami perdarahan pervaginam yang hebat dan tidak teratur $(28 \%)$.

3. Dari uji analisis menggunakan Chi Kuadrat didapatkan hasil $\chi^{2}$ hitung 7,12 dan $\chi^{2}$ tabel dengan $\alpha=0,05$ dan $\mathrm{dk}=2$ didapatkan nilai $\chi^{2}$ tabel 5,991. Karena $\chi^{2}$ hitung $>\chi^{2}$ tabel maka $\mathrm{H}_{1}$ diterima yang artinya ada hubungan penggunaan AKDR dengan kejadian efek samping pada akseptor AKDR di Desa Kates Kecamatan Kauman Kabupaten Tulungagung.

Depdiknas. 2008. Kamus Besar Bahasa Indonesia. Jakarta : Gramedia Pustaka Utama

Everett, Suzanne. 2007. Buku Saku Kontrasepsi \& Seksual Reproduktif. Jakarta: EGC

Handayani, Sri. 2010. Buku Ajar Pelayanan Keluarga Berencana. Yogyakarta: Pustaka Rihama 
Hatcher, Robert A., 2015. Serba-Serbi Kontrasepsi Lengkap dan Praktis. Yogyakarta: Citra Pustaka

Hidayat Alimul A., 2010. Metode Penelitian Kebidanan \& Teknik Analisa Data. Jakarta: Salemba Medika

2012. Riset Keperawatan Dan Tehnik Penulisan Ilmiah. Jakarta: Salemba Medika.

Hidayati, Ratna. 2012. Metode Dan Teknik Penggunaan Alat Kontrasepsi. Jakarta: Salemba Medika

Judha. M. 2012. Teori Pengukuran Nyeri dan Nyeri Persalinan. Yogyakarta : Nuha Medika

Manuaba, Ida Ayu C., 2010. Ilmu Kebidanan, Penyakit Kandungan, dan KB untuk Pendidikan Bidan. Jakarta: EGC

Marmi, 2010. Buku Ajar Pelayanan KB. Yogyakarta: Pustaka Pelajar

Notoatmodjo Soekidjo. 2010. Metodologi Penelitian Kesehatan. Jakarta: Rineka Cipta.

Nursalam, 2013. Konsep Dan Penerapan Metodologi Penelitian Ilmu Keperawatan. Jakarta: Salemba Medika.

Rahardja, Mugia B. Jurnal Kesehatan Masyarakat, Volume 6. Nomor 3. Desember 2011. Hal 143.

Saifuddin, 2011. Buku Panduan Praktis Pelayanan Kontrasepsi. Jakarta: Yayasan Bina Pustaka Sarwono Prawirohardjo

Setiadi, 2007. Konsep Dan Penelitian Riset Keperawatan. Yogyakarta: Graha Ilmu.

Sugiyono, 2012. Statistik Untuk Penelitian. Bandung: Alfabeta
Sulistyawati, Ari. 2011. Pelayanan Keluarga Berencana. Jakarta: Salemba Medika

Uliyah, Mar'atul. 2010. AWAS KB! Panduan Aman dan Sehat Memilih Alat KB. Yogyakarta: INSANIA

Varney, H., Kriebs, J. M. \& Gegor, C. L. 2007. Buku Ajar Asuhan Kebidanan. Jakarta EGC

Wasis, 2008. Pedoman Riset Praktis Untuk Profesi Perawat. Jakarta: EGC

Wawan Dan Dewi., 2010. Teori Dan Pengukuran Pengetahuan, Sikap, Dan Prilaku Manusia. Yogyakarta:Nuha Medika.

WHO. 2006. Ragam Metode Kontrasepsi. Jakarta: EGC

BKKBN. 2011. Kamus Istilah Kependudukan \& Keluarga Berencana. Available from: http://www.bkkbn.go.id/arsip/Documents/P erpustakaan/Kamus\%20\%Istilah\%20KKB.p df [Accessed 25/07/2016]

BKKBN. 2015. Perhitungan Alokon Program KKBPK Tahun 2015. Available from: http://www.bkkbn.go.id/Documents/MATE RI\%20KOSI\%202014/KOSI\%20DEPUTI $\% 20 \mathrm{~KB} \% 20 \mathrm{KR} / \mathrm{PERHITUNGAN} \% 20 \mathrm{ALO}$ KON\%20TAHUN\%202015.pdf. [Accessed $16 / 04 / 2016]$

Mahdalena Br Taringan. 2013. Pengaruh Umur, Paritas, Efek Samping, Dan Dukungan Suami Terhadap Kelangsungan Pemakaian Alat Kontrasepsi Dalam Rahim Di Wilayah Kerja Puskesmas Kabanjahe Tahun 2013. Available from: http://repository.usu.ac.id/handle/12345678 9/46320\&sa $=$ U\&ved $=0$ ahUKEwjelcuRx7X OAhUiTI8KWHdCd4QFggHMAA\&usg=ADQjCNGm5jWr N0VeK34-8n r2I8PqMWQMA [Acessed 25/07/2016] 